\title{
PEMANFAATAN METODE WAVELET PADA ROBOT SEPAKBOLA BERBASIS MACHINE LEARNING GOOGLE TENSORFLOW
}

\author{
Aryanto $^{1,2}$, Melvi $^{1}$ \\ Teknik Elektro, Fakultas Teknik, Universitas Lampung, Bandar Lampung, Indonesia ${ }^{1}$ \\ email : uyaarya@gmail.com²
}

\begin{abstract}
Humanoid Football robot that will be investigated is a wheeled model developed with the ability to predict or prediction in a football field with high accuracy and image resolution. This robot is expected to be able to keep the goal for up to 25 minutes with a cruising reach of $100 \mathrm{~m}$. Also, the robot can monitor or monitor the desired area so that it can keep the goal from attacks from the opposing robot. This robot is expected to complete prediction missions towards the ball and autonomous monitoring without being controlled by the pilot. Robot control is carried out by a Ground Control Station (GCS) computer. The goalkeeper's robot process uses Google TensorFlow's machine learning technology that is integrated with the wavelet method to enable this robot to keep the goalposts from the area effectively and efficiently.
\end{abstract}

Keywords: robot, machine learning, prediction, Ground Control Station, wavelet method

\section{Abstrak}

Robot Humanoid Football yang akan diselidiki adalah robot model beroda yang dikembangkan dengan kemampuan untuk memprediksi atau prediksi di lapangan sepakbola dengan akurasi tinggi dan resolusi gambar. Robot ini diharapkan mampu menjaga tujuannya hingga 25 menit dengan daya jelajah $100 \mathrm{~m}$. Juga, robot dapat memonitor atau memonitor area yang diinginkan sehingga dapat menjaga tujuan serangan dari robot lawan. Robot ini diharapkan dapat menyelesaikan misi prediksi ke arah bola dan pemantauan otonom tanpa dikendalikan oleh pilot. Kontrol robot dilakukan oleh Ground Control Station (GCS) komputer. Proses robot kiper menggunakan teknologi pembelajaran mesin Google TensorFlow yang terintegrasi dengan metode wavelet untuk memungkinkan robot ini menjaga tiang gawang dari area secara efektif dan efisien.

Kata kunci: robot, pembelajaran mesin, prediksi, Ground Control Station, metode wavelet

\section{PENDAHULUAN}

Pengembangan robot sepakbola di indonesia saat ini sudah sangat pesat. Selain digunakan untuk keperluan kompetisi mahasiswa pada kegiatan lomba dan praktek, robot ini juga dapat difungsikan sebagai alat bantu mahasiswa dalam mempercepat proses pembelajaran mengenai dunia robotika[1].

Penggunaan robot penjaga gawang dalam pertandingan sebenarnya sangat berpengaruh besar karena tugas robot penjaga gawang ini adalah melakukan pendeteksian bola kemudian menjaga agar objek berupa bola berwarna orange tidak masuk ke daerah bertahan robot tersebut. Selain menahan bola dengan bagian badan dari robot tersebut robot juga dirancang agar mampu menggerakan lengan yang ada pada robot agar dapat bergerak dengan cepat ke arah bola yang bergerak menuju robot. Sehingga diperlukan metode yang efektif dan efisien dalam penentuan pergerakan lengan robot [2-5].

Prospek penelitian ini adalah bahwa sistem ini dapat dikembangkan dan diimplementasikan secara umum untuk masalah pendeteksian dan pergerakan roda dengan menggunakan sensor vision yang ada.

\section{GOOGLE TENSORFLOW}

TensorFlow merupakan platform gratis machine learning yang dikembangkan oleh Google [7], diperkenalkan dengan Bahasa Python. TensorFlow menyediakan sumber pustaka terbuka dan gratis yang didukung dengan baik untuk mendukung ML dan DL operasi. Manfaat dari TensorFlow adalah untuk komputasi aplikasi intensif, daripada menjalankan tindakan pada satu mesin dengan CPU tunggal
(Central Processing Unit), Tindakan TensorFlow dapat didistribusikan di banyak CPU, GPU (Unit Pemrosesan Grafik), beberapa mesin atau TPU (Unit Pemroses Tensor). Perhitungan numerik adalah dilakukan melalui pembuatan dan penggunaan grafik aliran data. Grafik aliran data ini juga dapat divisualisasikan menggunakan Rangkaian alat TensorBoard. Ada beberapa bahasa yang berbeda bisa dipilih untuk mengimplementasikan sistem ini, dengan bahasa yang didukung melalui perpustakaan (modul) yang telah dikembangkan untuk aplikasi Machine Learning dan Deep Learning. Namun Python adalah bahasa yang dipilih dalam penelitian ini; TensorFlow the Python library (modul). Berikut adalah contoh deteksi bola menggunakan TensorFlow:

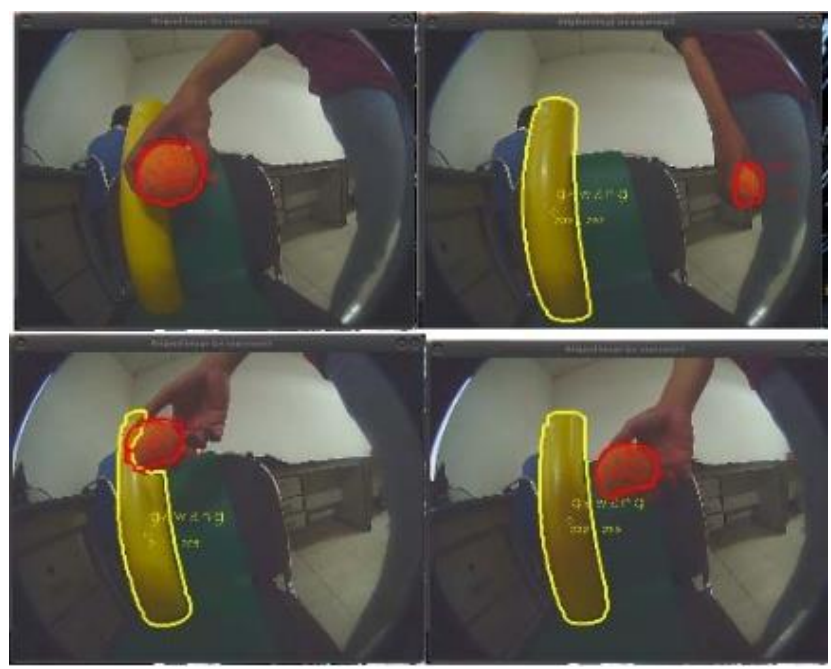

Gbr 1. Deteksi Bola Menggunakan TensorFlow 


\section{TRANSFORMASI WAVELET}

Transformasi wavelet telah diperkenalkan baru-baru ini dalam matematika, walaupun gagasan penting yang mendorong ke arah pengembangan ini sudah ada untuk periode waktu yang lama. Bagaimanapun juga, transformasi wavelet merupakan suatu transformasi linear yang hampir mirip dengan transformasi Fourier, dengan satu perbedaan penting: transformasi wavelet membolehkan penempatan waktu dalam komponen-komponen frekuensi yang berbeda dari sinyal yang diberikan. Transformasi Fourier berjendela (windowed Fourier transform) juga secara parsial mencapai tujuan seperti ini, tapi dengan sebuah keterbatasan dalam penggunaan fungsi lebar window yang ditetapkan. Pada kasus transformasi wavelet, analisa fungsifungsi, yang disebut wavelet, akan menyesuaikan lebar waktunya (time-width) terhadap frekuensinya. Sehingga, wavelet dengan frekuensi yang lebih tinggi akan menjadi sangat sempit dan wavelet dengan frekuensi yang lebih rendah akan menjadi lebih luas.

Sampai sekarang transformasi Fourier mungkin masih menjadi transformasi yang paling populer di area pemrosesan sinyal digital (PSD). Transformasi Fourier memberitahu kita informasi frekuensi dari sebuah sinyal, tapi tidak informasi waktu (kita tidak dapat tahu kapan frekuensi itu terjadi). Karena itulah transformasi Fourier hanya cocok untuk sinyal stationari (sinyal yang informasi frekuensinya tidak berubah menurut waktu). Transformasi wavelet dibagi menjadi dua jenis, yaitu transformasi wavelet kontinu dan transformasi wavelet diskrit.

Koefisien transformasi wavelet diskrit dari suatu gelombang dapat diperoleh dengan menerapkan DWT yang diberikan melalui persamaan :

$$
D W T(f, m, n)=\frac{1}{\sqrt{a_{0}^{m}}} \sum_{k} f(k) \psi *\left(\frac{n-k a_{0}^{m}}{a_{0}^{i n}}\right)
$$

dimana, parameter $a$ dan $b$ dalam persamaan (1) digantikan dengan $a_{0}^{m}$ dan $k a_{0}^{m}, k$ dan $m$ adalah variabel bilangan bulat positif. Dalam penggunaan suatu induk wavelet, DWT melakukan analisis detail melalui bagian frekuensi tinggi dari induk wavelet tersebut. Sedangkan analisis aproksimasi dilakukan melalui bagian frekuensi rendah dari induk wavelet [8-11].

\section{METODE}

Berikut ini adalah dimensi robot yang dibuat, adalah sebagai berikut :

\begin{tabular}{lc}
\multicolumn{2}{c}{ Tabel 1. Dimensi dan Ukuran Robot } \\
\hline \multicolumn{1}{c}{ Dimensi } & Ukuran \\
\hline Panjang & $40 \mathrm{~cm}$ \\
\hline Lebar & $40 \mathrm{~cm}$ \\
\hline Tinggi & $70 \mathrm{~cm}$ \\
\hline
\end{tabular}

Berikut adalah sketch rancangan robot tersebut :

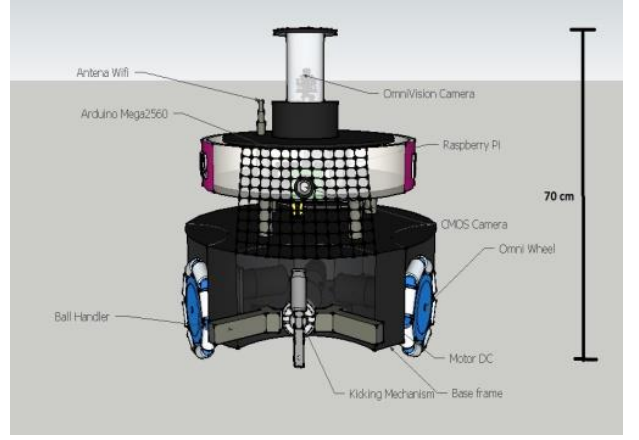

Gbr 2. Rancangan Robot Sepakbola

Objek utama dalam sistem pengendalian robot adalah pendeteksian pada bola, pemain lawan, dan garis lapangan. Dalam menentukan pergerakan robot, camera omnivison melihat daerah sekitar untuk menentukan objek sekitar baik itu tim lawan, tim sepihak dan garis batas lapangan, setelah mendapatkan data didaerah sekitar maka dilanjutkan ke komputer untuk diolah data yang diambil dan diteruskan ke pergerakan omniwheel sehingga dapat bergerak menghindari benturan yang tidak diinginkan. Pada mekanisme cara menendang yaitu robot menggunakan camera omnivision untuk melihat objek bola selanjutnya diproses di komputer untuk diteruskan ke front camera dan kompas untuk mempresisikan lokasi gawang lawan dan kemudian robot dapat menendang bola. Untuk dapat mengoper bola dalam satu tim, setiap robot memiliki komunikasi wireless dalam Access point pada masing-masing robot. Pada saat robot mengetahui bahwa bola berada di daerah sendiri, maka masing-masing robot mampu kembali keposisi bertahan dan mengambil alih bola untuk diteruskan ke daerah lawan. Robot penjaga gawang memiliki perbedaan dengan robot penyerang yaitu pada struktur mekanik robot pada bagian atas, ditambahkan dengan lengan yang dapat memanjang ke atas, ke kiri, ke kanan.

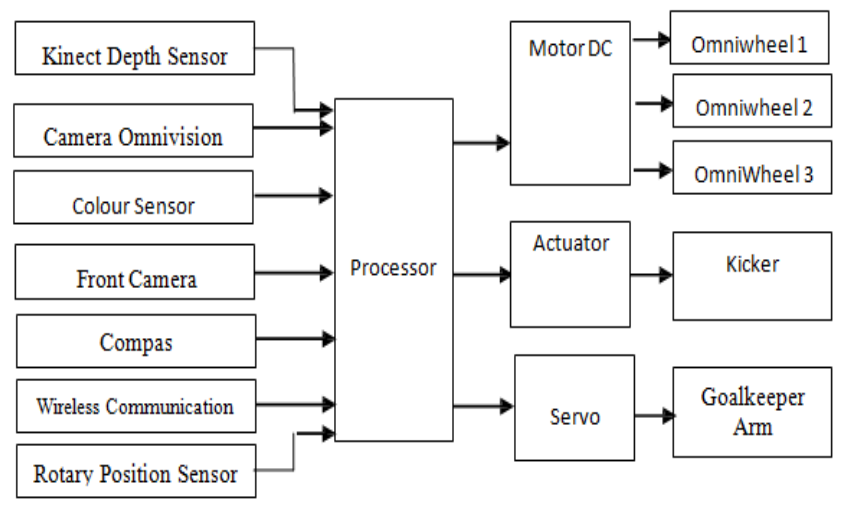

Gbr 3. Diagram Pengendali Robot Sepakbola 


\section{Robot SePAKbola Berbasis Machine LEARNING GOOGLE TENSORFLOW}

Penelitian yang telah dilakukan dibagi dalam tahapan merealisasikan sensor vision pada objek menggunakan pixel pada berbagai kondisi. Pada tahap ini objek yang akan dideteksi adalah berbagai objek benda. Objek diberikan range pixel yang berbeda-beda. Tahap berikutnya akan merealisasikan Robot penjaga gawang pada objek menggunakan alat berbasis Google TensorFlow pada skala laboratorium. Berikut adalah hasil dari perancangan robot beroda yang telah dibuat:

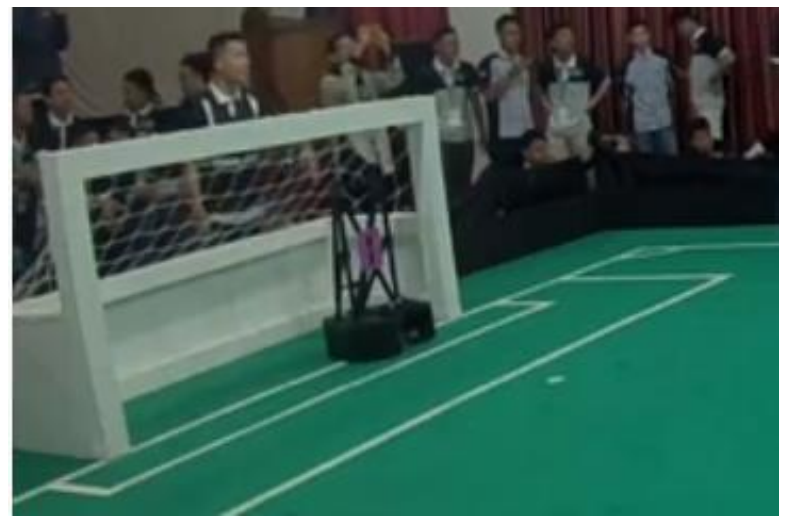

Gbr 4. Robot Sepakbola Beroda Universitas Lampung

Berikut adalah hasil dari learning/ pembelajaran menggunakan google TensorFlow pada robot Sepakbola:

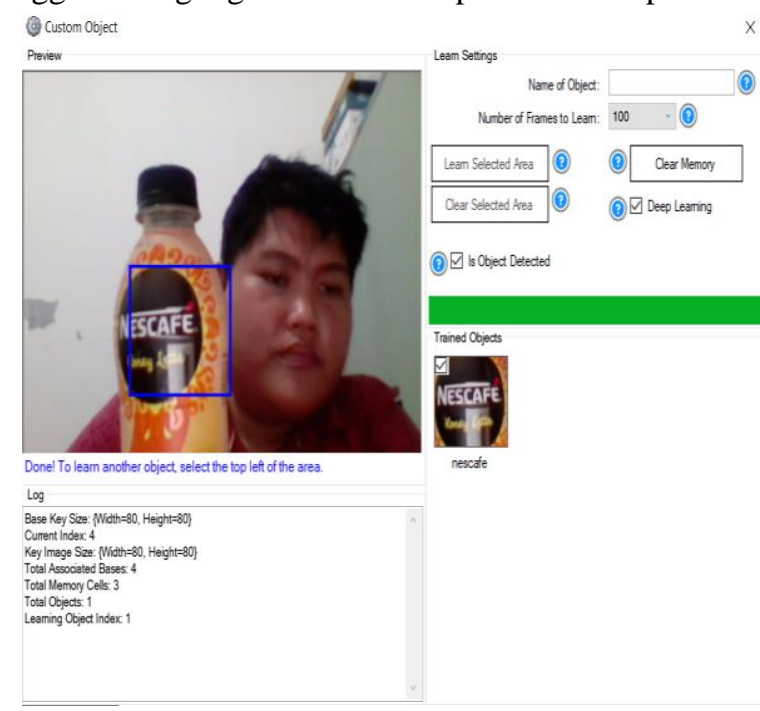

Gbr 5. Robot Sepakbola berhasil Mentracking Botol minuman dengan Baik

Setelah robot berhasil robot dapat menemukan botol Minuman dilakukan penentuan prediksi arah datangnya bola dengan melempar botol minuman ke arah robot agar diketahui apakah robot responsive atau tidak dengan melacak arah datangnya botol minuman kearahnya. Dari 100 kali percobaan robot hanya berhasil 67 persen yakni 67 kali mengenali botol minuman yang dilempar secara acak dan gagal 33 kali. Berikut adalah grafik keberhasilan robot dalam mengenali botol minuman.

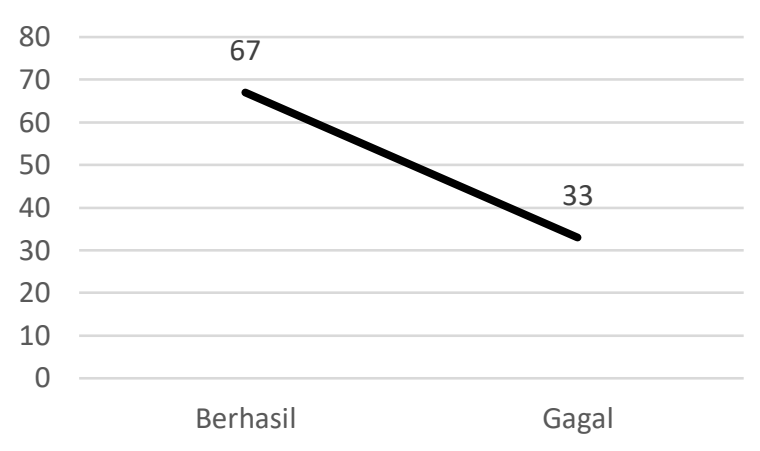

Gbr 6. Tingkat Keberhasilan Robot Sepakbola Memprediksi Kedatangan Botol Minuman

\section{KESIMPULAN}

Berdasarkan dari hasil perancangan dan pembuatan robot sepakbola berbasis machine learning TensorFlow, maka dapat kita peroleh bahwa robot dapat berjalan dengan baik sesuai dengan perancangan dan pembuatan robot tersebut. Robot relatif baik dan efisien dalam melacak objek dengan keberhasilan menemukan botol minuman dengan keberhasilan 67 kali. Namun perlu penelitian lanjutan untuk robot dapat dengan efektif dalam melacak objek tersebut seperti hanya melihat warna bukan dengan pembelajaran menggunakan machine learning TensorFlow tersebut. adalah robot model beroda yang dikembangkan dengan kemampuan untuk memprediksi atau prediksi di lapangan sepakbola dengan akurasi tinggi dan resolusi gambar. Robot ini diharapkan mampu menjaga tujuannya hingga 25 menit dengan daya jelajah $100 \mathrm{~m}$. Juga, robot dapat memonitor atau memonitor area yang diinginkan sehingga dapat menjaga tujuan serangan dari robot lawan. Robot ini diharapkan dapat menyelesaikan misi prediksi ke arah bola dan pemantauan otonom tanpa dikendalikan oleh pilot.

\section{DAFTAR PUSTAKA}

[1] N. Muhammad, D. Fofi and S. Ainouz, "Current state of the art of vision based SLAM," in Proceedings of the SPIE, California, 2009, pp. 72510F-72510F-12.

[2] J. AUlinAS, Y. PETILlOT, J. SALVI, and X. LLADÓ, "The SLAM problem: a survey," in Proceeding of the 2008 conference on Artificial Intelligence Research and Development: Proceedings of the 11th International Conference of the Catalan Association for Artificial Intelligence, Costa Brava, 2008, pp. 363-371.

[3] R. Triebel and W. Burgard, "Improving simultaneous mapping and localization in 3D using global constraints," in Proceedings of the 20th national conference on Artificial intelligence, Pennsylvania, 2005, pp. 1330-1335.

[4] J. J. Leonard and H. F. Durrant-Whyte, "Simultaneous map building and localization for an autonomous mobile robot," in Proc. IEEE Int. Workshop on Intelligent Robots and systems, Osaka, 1991, pp.14421447.

[5] D. Filliat and J. A. Meyer, "Map-based navigation in mobile robots. i. a review of localization strategies," Journal of Cognitive Systems Research, vol. 4, no. 4, pp. 243-282, Dec. 2003. 
[6] J. J. Leonard and H. F. Durrant-Whyte, "Mobile robot localization by tracking geometric beacons," IEEE Trans. Robotics and Automation, vol. 7, no. 3, pp. 376382, Jun. 1991.

[7] Google. Tensorflow.

Internet: https://www.TensorFlow.org. diakses tanggal 6 Februari 2020

[8] Ó. M. Mozos, A. Gil, M. Ballesta, and O. Reinoso, "Interest point detectors for visual SLAM," in 12th Conference of the Spanish Association for Artificial Intelligence, Salamanca, pp. 170-179, Nov. 2007.

[9] C. Harris, M. Stephens, "A combined corner and edge detector," in Proceedings of the Fourth Alvey Vision Conference, Manchester, 1988, pp. 147-151.

[10] H. Bay, T. Tuytelaars, and L. V. Gool, "SURF: speeded up robust features," in Proceedings of the 9th European Conference on Computer Vision, Graz, 2006, pp. 404417.

[11] D. G. Lowe, "Distinctive image features from scaleinvariant keypoints," International Journal on Computer Vision, vol. 60, no. 2, pp. 91-110, Jan. 2004.

\section{BIOGRAFI PENULIS}

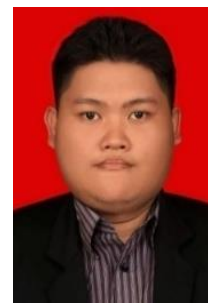

Informatika.
Aryanto, lahir di Bandar Lampung, 21 Juni 1990. Menempuh pendidikan S1 di Universitas Lampung (2008-2012), dan menempuh pendidikan S2 di Institut Teknologi Bandung (2013-2016). Sekarang bekerja sebagai pengajar di Teknik Elektro Universitas Lampung, dilaboratorium Teknik Telekomunikasi dan Teknik 